\title{
2-Aminoethoxydiphenyl Borate as a Common Activator of TRPV1, TRPV2, and TRPV3 Channels
}

\author{
C. K. Colton and M. X. Zhu \\ Department of Neuroscience and Center for Molecular Neurobiology, The Ohio State University, \\ Columbus $\mathrm{OH}, 43210$, USA
}

\begin{abstract}
2-Aminoethoxydiphenyl borate (2APB) had been depicted as a universal blocker of transient receptor potential (TRP) channels. While evidence has accumulated showing that some TRP channels are indeed inhibited by $2 \mathrm{APB}$, especially in heterologous expression systems, there are other TRP channels that are unaffected or affected very little by this compound. More interestingly, the thermosensitive TRPV1, TRPV2, and TRPV3 channels are activated by 2APB. This has been demonstrated both in heterologous systems and in native tissues that express these channels. A number of 2APB analogs have been examined for their effects on native storeoperated channels and heterologously expressed TRPV3. These studies revealed a complex mechanism of action for $2 \mathrm{APB}$ and its analogs on ion channels. In this review, we have summarized the current results on 2APB-induced activation of TRPV1-3 and discussed the potential mechanisms by which $2 \mathrm{APB}$ may regulate TRP channels.
\end{abstract}

\section{Keywords}

2APB; Transient receptor potential; TRPC; Store-operated channel; Thermosensitive channel

\section{Introduction}

2-Aminoethoxydiphenyl borate (2APB) was first introduced to the biological community in 1997 as an inhibitor of inositol 1,4,5-trisphosphate receptors (IP3Rs) (Maruyama et al. 1997). It was later demonstrated to also block store-operated calcium entry (SOCE) (Dobrydneva and Blackmore 2001; Prakriya and Lewis 2001; Diver et al. 2001; Trebak et al. 2002). Since members of the canonical transient receptor potential (TRPC) family, as well as TRPV6, have been suggested to participate in SOCE (Zhu et al. 1996; Yue et al. 2001), their sensitivity to 2APB has been tested in heterologous expression systems. To date, the inhibition by 2APB has been documented for TRPC1, C3, C5, C6, and C7 (Delmas et al. 2002; Trebak et al. 2002; Hu et al. 2004; Xu et al. 2005; Lievremont et al. 2005). The effect of 2APB on TRPV6 is dependent on the expression level and the host cell type. While the drug slightly increased the constitutive activity of TRPV6 overexpressed in HEK293 and rat basophilic leukemia cells, it indeed blocked the store-operated component acquired by 
the low expression of TRPV6 in the latter cell type (Voets et al. 2001; Schindl et al. 2002). Furthermore, the inhibition by 2APB of TRPC $3, \mathrm{C} 6$, and C7 is dependent on the mode, and perhaps the degree, of activation and is often incomplete (Lievremont et al. 2005). In chicken DT40 cells, the ectopically expressed human TRPC3 was, instead, activated by 2APB (Ma et al. 2003).

Despite the limited number of studies showing consistent inhibition of ectopically expressed TRPC and TRPV6 channels by 2APB, there is ample evidence on 2APB-induced inhibition of endogenous channels presumably composed of various TRPC subunits (Tozzi et al. 2003; Sydorenko et al. 2003; Lucas et al. 2003). In addition, the magnesium-inactivated conductance, which is likely formed by TRPM7, is also inhibited by 2APB (Hermosura et al. 2002; Prakriya and Lewis 2002). In light of these observations, 2APB became recognized as a universal TRP channel blocker (Clapham et al. 2001). However, experimental evidence for this "label" has been scarce. In addition to the data described above, an inhibitory effect of 2APB has been shown for TRPM3, TRPM7, TRPM8, and TRPP2 (Xu et al. 2005; Hanano et al. 2004; Hu et al. 2004; Koulen et al. 2002). However, TRPM2 is unaffected and TRPV5 is only slightly inhibited by $100 \mu \mathrm{M}$ 2APB (Nilius et al. 2001; Xu et al. 2005). More interestingly, 2APB is able to activate three thermosensitive members of the TRPV family, TRPV1-3 (Hu et al. 2004).

\section{2APB Is a Common Activator of TRPV1, V2, and V3}

The TRPV family has been studied extensively in recent years due to its involvement in temperature and pain sensation. TRPV1, V2, V3, and V4 are activated by high temperatures from warm to noxious heat with temperature thresholds of $43^{\circ} \mathrm{C}, 52^{\circ} \mathrm{C}, 31^{\circ} \mathrm{C}$, and $25^{\circ} \mathrm{C}$, respectively. Interestingly, they are expressed not only in the peripheral nervous system where they sense temperature and pain, but also in a wide variety of tissues that are not exposed to significant temperature fluctuation. For example, TRPV1 is expressed in astrocytes and other regions of brain, spinal cord, skin, and tongue; TRPV2 is in brain, vascular smooth muscle cells, intestines, and macrophages; TRPV3 is in keratinocytes, brain, and testis; and TRPV4 is in brain, skin, kidney, liver, trachea, heart, hypothalamus, and airway smooth muscle cells (Patapoutian et al. 2003; Doly et al. 2004; Muraki et al. 2003; Kashiba et al. 2004; Kim et al. 2003; Xu et al. 2002; Peier et al. 2002; Jia et al. 2004). TRP channels are often activated by multiple forms of stimuli. This polymodality, combined with the wide range of tissue distributions, suggests that these channels are involved in many different cellular and physiological functions.

The original drive for testing the effect of $2 \mathrm{APB}$ on the TRPV channels was to verify whether 2APB was a universal blocker of all TRP channels. This was done using HEK293 cells that had been transiently transfected with the complementary DNA (cDNA) for all members of the TRPV family (TRPV1-6) in different wells of 96-well plates. The cells were loaded with Fluo4 and assayed for intracellular $\mathrm{Ca}^{2+}$ changes using a fluorescence plate reader (FLEXStation, Molecular Devices). To our surprise, 2APB $(0.5 \mathrm{mM})$ evoked a robust increase in Fluo4 fluorescence in cells transfected with TRPV1, V2, and V3. The endogenous response in vector-transfected cells was small and indistinguishable from those in cells that expressed TRPV4, V5, and V6. This initial data suggested that 2APB might be a 
common activator of TRPV1-3. Concentration-response curves to 2APB obtained from the $\mathrm{Ca}^{2+}$ assay at $32^{\circ} \mathrm{C}$ yielded $\mathrm{EC}_{50}$ values of $114 \pm 8,129 \pm 13$, and $34 \pm 12 \mu \mathrm{M}$ for TRPV1, V2, and V3, respectively. Subsequent experiments were designed to confirm this finding and further characterize the effect of 2APB on TRPV1-3 using electrophysiological methods (Hu et al. 2004).

\subsection{APB as an Activator of TRPV1}

In whole-cell recordings, 2APB dose-dependently activated currents in HEK293 cells that expressed mouse TRPV1. Control cells did not show any response to 2APB up to $3 \mathrm{mM}$. Under similar conditions, TRPC6 and TRPM8 currents were inhibited by 2APB. In order to confirm that the stimulatory effect of 2APB on TRPV1 was not a unique property of HEK293 cells, we also studied this effect in Xenopus oocytes injected with cRNA of mouse TRPV1. At $300 \mu \mathrm{M}, 2 \mathrm{APB}$ elicited an inward current at $-40 \mathrm{mV}$ that was completely blocked by $3 \mu \mathrm{M}$ ruthenium red (RR) but only partially blocked by $30 \mu \mathrm{M}$ capsazepine (approx. 30\%). Interestingly, $30 \mu \mathrm{M}$ of capsazepine completely blocked the currents evoked by $1 \mu \mathrm{M}$ capsaicin in the same cell, suggesting that the site of action for $2 \mathrm{APB}$ and capsaicin may be different.

A characteristic feature associated with the polymodality of TRPV1 is that known activators such as heat, protons, and capsaicin act synergistically. This is also true for 2APB in respect to other TRPV1 activators. In HEK293 cells, coapplication of $0.3 \mu \mathrm{M}$ capsaicin and $100 \mu \mathrm{M}$ $2 \mathrm{APB}$, or $100 \mu \mathrm{M} 2 \mathrm{APB}$ at $\mathrm{pH} 6.5$, greatly increased the TRPV1 current at $-100 \mathrm{mV}$ more than 20-fold as compared to the stimulation with capsaicin, $2 \mathrm{APB}$, or the weak acid ( $\mathrm{pH} 6.5$ ) alone. In Xenopus oocytes expressing TRPV1, $100 \mu \mathrm{M}$ 2APB left-shifted the dose-response curve for capsaicin 3.8-fold and the $\mathrm{pH}$ dependence 6.6-fold. Conversely, capsaicin $(0.3 \mu \mathrm{M})$ and weak acid ( $\mathrm{pH}$ 6.5) also left-shifted the dose-response curve to 2APB 9.3- and 2.0-fold, respectively. Furthermore, about a 9 -fold increase in current at $-40 \mathrm{mV}$ was obtained when $100 \mu \mathrm{M} 2 \mathrm{APB}$ was applied at $40^{\circ} \mathrm{C}$ as compared to $22^{\circ} \mathrm{C}$ (Hu et al. 2004).

Chung et al. (2004b, 2005) also examined the effect of 2APB on TRPV channels. Although the initial study only showed a slight activation of TRPV1 by $100 \mu \mathrm{M} 2 \mathrm{APB}$ at very positive potentials, subsequent experiments indeed confirmed a robust 2APB-induced intracellular $\mathrm{Ca}^{2+}$ increase via rat TRPV1 stably expressed in HEK293 cells at a slightly higher drug concentration of $320 \mu \mathrm{M}$.

\subsection{APB as an Activator of TRPV2}

2APB-evoked whole-cell currents have been observed in HEK293 cells that expressed mouse TRPV2 (Hu et al. 2004, 2006). At $22^{\circ} \mathrm{C}$, this activation was very weak at $1 \mathrm{mM}$, but became strong at $3 \mathrm{mM} 2 \mathrm{APB}$. The currents showed weak double rectification and were blocked by $3 \mu \mathrm{M}$ RR. Chung et al. (2005) also confirmed the effect of 2APB ( $320 \mu \mathrm{M})$ on eliciting intracellular $\mathrm{Ca}^{2+}$ increase at the room temperature in HEK293 cells expressing rat TRPV2. On the other hand, for an endogenous channel encoded by mouse TRPV2 in the F-11 hybridoma derived from rat dorsal root ganglia (DRG) and mouse neuroblastoma, 100 $\mu \mathrm{M} 2 \mathrm{APB}$ did not significantly change the temperature threshold of current activation at -60 
$\mathrm{mV}$ (Bender et al. 2005), indicating that there may be other requirement(s) for the activation of TRPV2 by $2 \mathrm{APB}$.

\subsection{APB as an Activator of TRPV3}

2APB-evoked TRPV3 currents have been shown in both HEK293 cells and Xenopus oocytes (Hu et al. 2004, 2006). In HEK293 cells that expressed mouse TRPV3, 2APB (30$300 \mu \mathrm{M})$ invoked dually rectifying currents (stronger in outward direction). RR $(3 \mu \mathrm{M})$ blocked these currents in the inward direction and potentiated them at potentials higher than $40 \mathrm{mV}$. Infusion of $1 \mathrm{mM}$ 2APB into the cell through the patch pipette for more than $6 \mathrm{~min}$ failed to elicit any current while subsequent application of 2APB in the bath elicited TRPV3 currents, indicating that 2APB acts from the extracellular side. In Xenopus oocytes injected with the cRNA for mouse TRPV3, $300 \mu \mathrm{M} 2 \mathrm{APB}$ activated an inward current at $-40 \mathrm{mV}$, which was blocked by $3 \mu \mathrm{M}$ RR but not by $10 \mu \mathrm{M}$ capsazepine. In addition, although a $40^{\circ} \mathrm{C}$ temperature challenge did not invoke a significant current, application of $100 \mu \mathrm{M} 2 \mathrm{APB}$ at $40^{\circ} \mathrm{C}$ invoked a current that was $35 \pm 6$ times in amplitude of that induced by the same concentration at $22^{\circ} \mathrm{C}$. These data confirm that TRPV 3 is activated by 2 APB and 2 APB strongly potentiates the thermal response of TRPV3.

Chung et al. (2004b) also showed that in HEK293 cells expressing mouse TRPV3, $32 \mu \mathrm{M}$ 2APB elicited slowly developing currents that were reversible and sensitized with successive $2 \mathrm{APB}$ application. Dose-response curves showed $\mathrm{EC}_{50}$ values of $28.3 \mu \mathrm{M}$ at +80 $\mathrm{mV}$ and $41.6 \mu \mathrm{M}$ at $-80 \mathrm{mV}$, which are within the range $(34 \pm 12 \mu \mathrm{M})$ we obtained from the $\mathrm{Ca}^{2+}$ assay. Interestingly and similar to our data, at low 2APB concentrations, the TRPV3 currents exhibited strong outward rectification, with dual rectification gradually increasing at greater than $10 \mu \mathrm{M} 2 \mathrm{APB}$. This change in the current-voltage (IV) relationship indicates a relatively strong and near maximal activation of TRPV3 by the high concentrations of 2APB. The synergy between $2 \mathrm{APB}$ and heat was also documented by the 6-fold increase in current amplitude in response to a $37^{\circ} \mathrm{C}$ heat challenge by $1 \mu \mathrm{M} 2 \mathrm{APB}$, a concentration insufficient to cause TRPV 3 activation at $24^{\circ} \mathrm{C}$.

In single-channel analysis of inside-out membrane patches excised from TRPV3-expressing HEK293 cells, $1 \mu \mathrm{M} 2$ APB evoked single-channel openings that were more prolonged than those evoked by heat. The inward and outward slope conductance was 201 and $147 \mathrm{pS}$, significantly smaller than those elicited by heat at $39^{\circ} \mathrm{C}$, which are 337 and $256 \mathrm{pS}$, respectively. The unitary amplitude of single-channel openings was determined to have a linear relationship with temperature, and extrapolation of the currents observed with $2 \mathrm{APB}$ at $24^{\circ} \mathrm{C}$ and those observed by $39^{\circ} \mathrm{C}$ alone revealed that the currents resulted from the opening of the same channel (Chung et al. 2004b).

\subsection{The Stimulatory Effect of 2APB on Native Tissues}

2APB-evoked currents have been demonstrated in neurons from rat DRG and nodose/ jugular ganglia (Hu et al. 2004; Gu et al. 2005). In capsaicin-sensitive neurons, $300 \mu \mathrm{M}$ 2APB directly activated currents that were blocked by $3 \mu \mathrm{M} R \mathrm{R}$ and to a lesser extent by 10 $\mu \mathrm{M}$ capsazepine. At 30 and $100 \mu \mathrm{M}, 2 \mathrm{APB}$ also potentiated the response to $\mathrm{pH} 6.5$ and the effect was only partially blocked by $10 \mu \mathrm{M}$ capsazepine. In addition, $30 \mu \mathrm{M} 2 \mathrm{APB}$ strongly 
potentiated the response to $0.3 \mu \mathrm{M}$ capsaicin and the current was completely blocked by capsazepine. These data show not only that native TRPV1 channels in rat DRG are activated by $2 \mathrm{APB}$, but that the pharmacology of ectopically expressed TRPV1 is similar to that of native channels.

Similar to DRG neurons, 2APB (30-300 $\mu \mathrm{M})$ invoked dose-dependent inward current at -70 $\mathrm{mV}$ in cultured capsaicin-sensitive rat pulmonary neurons and the current was sensitive to $\mathrm{RR}$ and capsazepine ( $\mathrm{Gu}$ et al. 2005). In addition, intravenous bolus injection of 2APB elicited pulmonary chemoreflex responses, characterized by apnea, bradycardia, and hypotension in anesthetized, spontaneously breathing rats. Although these data cannot distinguish the relative contributions of TRPV1, V3, and perhaps V2, in these responses, similar studies using 2APB and TRPV knockout mice could determine the importance of individual TRPV members in the pulmonary chemoreflex and other sensory responses. In fact, by comparing the heat responses of skin-saphenous nerve preparation and cultured DRG neurons from wild type and trpv $1^{-/-}$mice, Zimmermann et al. (2005) showed that the 2APB-induced sensitization to thermal stimulation in mouse C-fibers was a TRPV1facilitated process.

Chung et al. (2004b) have tested the response of cultured mouse keratinocytes to 2APB. Immunostaining revealed that TRPV3 was expressed in most of these cells. However, heatevoked TRPV3-like sensitizing currents are rarely detectable (5/189 cells; Chung et al. 2004a). Application of $100 \mu \mathrm{M} 2 \mathrm{APB}$ at $40^{\circ} \mathrm{C}$ resulted in outwardly rectifying currents that were sensitized upon repetitive heat challenges in the majority of the wildtype (22/27) and trpv $4^{-/-}$(23/30) keratinocytes (Chung et al. 2004b). RR $(10 \mu \mathrm{M})$ inhibited inward currents evoked by $2 \mathrm{APB}$ at $42^{\circ} \mathrm{C}$ in keratinocytes derived from $\operatorname{trp} v 4^{-/-}$mice. Together, these data confirm that $2 \mathrm{APB}$ can sensitize the response of TRPV3 to heat in mouse keratinocytes independent of TRPV4. More recently, the 2APB-induced activation of native TRPV3 channel and potentiation of its heat response in mouse keratinocytes was confirmed by another group (Moqrich et al. 2005). Unfortunately, whether these responses are missing in trpv $3^{-/-}$keratinocytes was not reported.

Guatteo et al. (2005) have shown the expression of TRPV3 and V4 in temperature-sensitive dopaminergic neurons of rat substantia nigra pars compacta. Both warming and application of 2APB were found to increase the intracellular $\mathrm{Ca}^{2+}$, suggesting a role for TRPV3 in $\mathrm{Ca}^{2+}$ homeostasis near physiological temperatures in these cells.

\section{The Effects of 2APB Analogs on TRPV Channels}

2APB analogs were first studied in order to identify blockers for $\mathrm{Ca}^{2+}$ influx induced by thrombin in human platelets, a process that is believed to involve TRPC1 (Rosado et al. 2002). Dobrydneva and Blackmore (2001) showed that like 2APB, diphenylboronic anhydride (DPBA) and 2,2-diphenyltetrahydrofuran (DPTHF) (see Fig. 1 for structures) could inhibit the thrombin-induced $\mathrm{Ca}^{2+}$ signal with a similar affinity as $2 \mathrm{APB}$. This had led Chung et al. (2005) to explore the possibility that these 2APB analogs would activate TRPV3. Using $\mathrm{Ca}^{2+}$ imaging, they showed that $100 \mu \mathrm{M}$ DPBA, but not $100 \mu \mathrm{M}$ DPTHF, caused a rise in intracellular $\mathrm{Ca}^{2+}$ in HEK293 cells expressing TRPV1, V2, or V3. 
Interestingly, $100 \mu \mathrm{M}$ DPTHF inhibited the response evoked by $100 \mu \mathrm{M} 2 \mathrm{APB}$ and $100 \mu \mathrm{M}$ DPBA by $73.2 \%$ and $93.2 \%$, respectively, in TRPV3 cells but not in TRPV1 and TRPV2 cells. Even at $500 \mu \mathrm{M}$ DPTHF, the inhibition was $25.2 \%$ and $33.2 \%$ for TRPV1 and V2, respectively. Thus, DPBA activates TRPV1, V2, and V3 in a similar fashion as 2APB, but DPTHF has an opposite action and may be more selective for TRPV3.

In whole-cell patch clamp studies of TRPV3 expressed in HEK293 cells, Chung et al. (2005) demonstrated that $32 \mu \mathrm{M}$ DPBA evoked outwardly rectifying currents that became dually rectifying with successive application of the drug. In addition, DPBA-evoked currents were blocked by DPTHF ( $58.9 \%$ and $90.8 \%$ inhibition at +80 and $-80 \mathrm{mV}$, respectively) or $10 \mu \mathrm{M} R \mathrm{RR}(99 \%$ at $-80 \mathrm{mV})$. A dose-response analysis of DPBA yielded $\mathrm{EC}_{50}$ values of $64.1 \mu \mathrm{M}$ and $85.1 \mu \mathrm{M}$ at +80 and $-80 \mathrm{mV}$, respectively. The authors also noted an inhibitory effect at high $(>100 \mu \mathrm{M})$ DPBA and 2APB concentrations, which is characterized by a decline in current amplitude at $1 \mathrm{mM}$ as compared to $0.3 \mathrm{mM}$ DPBA, a desensitization in the continued presence of the drug, and a strong rebound immediately after the washout. The IV relationship during the rebound appeared linear, indicative of a near-maximal activation of TRPV3. The most likely explanation is that DPBA has two sites of action, where one is stimulatory and the other inhibitory. Although a single site of action being modulated by an intrinsic "desensitization" pathway is also possible, the rebound at the washout and the fact that TRPV3 is sensitized but not desensitized upon repetitive stimulation make it unlikely.

The inhibitory action of DPTHF on TRPV3 also appeared to have two kinetic components. The $\mathrm{IC}_{50}$ values at $-80 \mathrm{mV}$ were $6.0 \mu \mathrm{M}$ and $151.5 \mu \mathrm{M}$ and those at $+80 \mathrm{mV}$ were $10.0 \mu \mathrm{M}$ and $226.7 \mu \mathrm{M}$ for the first and the second components, respectively. In light of the facts that 2APB, DPBA, and DPTHF all blocked SOCE in platelets, and that they each have the ability to inhibit TRPV3 at high concentrations, it is possible that the low-affinity site of DPTHF is shared by 2APB and DPBA at high $(>100 \mu \mathrm{M})$ concentrations and is inhibitory for all three compounds. This accounts for the rebound during washout. The stimulatory site may also be shared by the three compounds with similar, but nonetheless relatively high, affinities. Hence, they could compete for binding to the same site. However, a structural feature important for activation may be lacking in DPTHF, resulting in inhibition even though it is bound to the "stimulatory site," especially in the presence of other stimulating compounds. Indeed, $100 \mu \mathrm{M}$ DPTHF was found to potentiate the heat-evoked response of TRPV3 (Chung et al. 2005). Thus, the complex activation/inhibition phenomenon observed with the $2 \mathrm{APB}$ analogs could be a result of dual bindings to separate stimulatory and inhibitory sites with different affinities.

\section{Possible Mechanisms of Action of 2APB}

How 2APB modulates TRP channels is still a mystery. The following sections consider the structural features of the compound, the possible target or binding site(s) on the channel subunits or other protein components associated with the channel complex, and the environment, mainly the lipid bilayers, that surrounds the channels. 


\subsection{Structural Considerations}

Due to the ability of $2 \mathrm{APB}$ to form an $\mathrm{N} \rightarrow \mathrm{B}$ coordinate bond, this molecule can exist in several different states (Fig. 1). Analyses on 2APB and its analogs by crystallography (Rettig and Trotter 1976), $\mathrm{p} K_{\mathrm{b}}$ values in aqueous solution (Dobrydneva and Blackmore 2001), and nuclear magnetic resonance (NMR) (Dobrydneva et al. 2006) support the idea that $2 \mathrm{APB}$ exists predominantly in the monomer ring structure as shown in Fig. 1, with the ethanolamine side chain forming a five-membered boroxazolidine heterocyclic ring (Strang et al. 1989; Dobrydneva and Blackmore 2001). The fact that 2APB can block the intracellularly located IP3Rs is consistent with the monomer ring structure. The open chain form would not be expected to pass through the membrane readily because the nitrogen of the ethanolamine side chain is most likely protonated in order to neutralize the free electron pair. 2APB can also form dimers (Nöth 1970; van Rossum et al. 2000). It should be considered that the ability of $2 \mathrm{APB}$ to switch between these different forms may also be important for its functional ability to activate or block TRP channels.

The boron on $2 \mathrm{APB}$ allows for the formation of coordinate bonds between the electrophilic boron and nucleophiles. 2APB and its boron-containing analogs could form either $\mathrm{N} \rightarrow \mathrm{B}$ or $\mathrm{O} \rightarrow \mathrm{B}$ coordinate bonds with amino acids that contain amines, imidazoles, and carboxyl groups on TRP channels. Interestingly, even though dimethyl 2APB (Fig. 1) blocked the thrombin-induced SOCE in platelets (Dobrydneva et al. 2006), a nonboron analog with two methyl groups on the secondary amine nitrogen, diphenhydramine, was ineffective in blocking SOCE in platelets (Dobrydneva and Blackmore 2001) and in activating TRPV3 expressed in HEK293 cells (Chung et al. 2004b). It would be interesting to test if dimethyl 2APB activates TRPV3. A positive effect would suggest that boron and/or ring formation is necessary for the stimulatory action of 2APB analogs, since the tertiary carbon and the secondary amine nitrogen of diphenhydramine are unable to make the ring closure like the $\mathrm{N} \rightarrow \mathrm{B}$ coordinate bond of the $2 \mathrm{APB}$ monomer ring (Fig. 1). The blocking and potentiating effects of DPTHF on TRPV3 (Chung et al. 2005), as well as the ability of several other nonboron analogs of 2APB to block SOCE in platelets (Dobrydneva et al. 2006), suggests that the boron may not be necessary, at least for binding to TRP channels or a critical auxiliary component(s) of the channel complex. However, without the boron, the compound may not be sufficient to activate the channel because heating appears to be necessary to reveal the stimulatory effect of the nonboron analog, DPTHF, on TRPV3 (Chung et al. 2005).

\subsection{Site(s) of Action}

Several lines of evidence favor the existence of at least two binding sites or sites of action for 2APB and its analogs, with one being stimulatory and the other inhibitory. First, at low concentrations, $2 \mathrm{APB}$ potentiated a native store-operated channel that is normally blocked by higher concentrations (Prakriya and Lewis 2001). Second, at above $100 \mu \mathrm{M}, 2 \mathrm{APB}$ - or DPBA-evoked TRPV3 currents tended to reach the maximum and then decrease in midresponse (Chung et al. 2005). This effect became more evident with increasing drug concentrations and led to an apparent decline in maximal current amplitude at $1 \mathrm{mM}$. Third, even though DPTHF is predominantly inhibitory, it potentiated the heat-induced TRPV3 currents (Chung et al. 2005). Fourth, the inhibition of DPBA-evoked TRPV3 currents by 
DPTHF extended over several orders of magnitude and had two kinetic components, indicative of two or more sites and/or mechanisms of action. One of these inhibitory actions could result from competition with 2 APB or DPBA for binding to the stimulatory site. This two-sites model could explain the concentration-dependent dual actions of the 2APB analogs. If the model holds true, modification of the 2APB structure may generate analogs with greater differences in the affinities to the stimulatory and the inhibitory sites and for different TRP subtypes, allowing for highly specific agonists and/or antagonists for some TRP channels. This exciting possibility warrants an extensive modification of $2 \mathrm{APB}$ analogs and evaluation of their effects on multiple TRP channels.

The plasma membrane side of action for 2APB is most likely extracellular. This is supported by the failure of intracellular injection of 2APB to activate any TRPV 1 current in Xenopus oocytes and intracellular infusion of 2APB and DPBA through patch pipettes to activate TRPV3 expressed in HEK293 cells in whole-cell experiments (Hu et al. 2004; Chung et al. 2005). In HEK293 cells, this same manipulation also failed to inhibit TRPC3 and TRPC5 channels (Trebak et al. 2002; Xu et al. 2005). In all cases, subsequent application of 2APB or DPBA in the bath had elicited either stimulation or inhibitory responses of the TRP channels. In excised inside-out patches, 2APB also failed to inhibit TRPC5 channel activity whereas in outside-out patches, the same concentration of 2APB effectively blocked the channel (Xu et al. 2005). One exception is that TRPV3 is activated by 2APB applied to the intracellular side of the inside-out patches (Chung et al. 2004b). This could be explained by the notion that the membrane permeable 2APB can accumulate at the pipette side (outside) even though it is applied to the exposed side of the membrane patch. Similar accumulation of 2 APB at the extracellular side will not occur in the outside-out or whole-cell configurations as the drug will be diluted by the bath solution or washed away by perfusion. However, this does not explain why 2APB failed to inhibit TRPC5 in the inside-out patches.

The available data also suggest that 2APB acts at a different site(s) from those of known TRPV1 agonists. First, TRPV2 and V3 are not activated by capsaicin but they are activated by 2 APB. Second, while capsazepine, a competitive antagonist of capsaicin, completely inhibited the capsaicin-induced response, it only partially blocked the 2APB-evoked activation of TRPV1. Third, superim-position of 2APB and capsaicin invoked responses that are more than additive to those elicited by each drug alone. This similar synergistic effect was also observed between 2 APB and weak acid, indicating that different mechanisms are involved for the activation of TRPV1 by 2APB, capsaicin, and protons. Most likely, a similar 2APB-binding pocket exists for TRPV1, V2, and V3, but it is very different from the vanilloid-binding pocket, which is mostly intracellular (see Tominaga and Tominaga 2005 for a review on vanilloid binding sites).

\subsection{Effects on Membrane Properties}

Several observations suggest that membrane properties strongly influence the activities of TRPV channels. First, TRPV1 is activated by a large number of lipophilic molecules, many of which bear no structural similarity (Calixto et al. 2005). Second, increasing the cholesterol content in HEK 293 cells shifted the temperature threshold of TRPV 1 from $42^{\circ} \mathrm{C}$ to $46^{\circ} \mathrm{C}$ (Liu et al. 2003). Third, phosphatidylinositol bisphosphate $\left(\mathrm{PIP}_{2}\right)$ has been proposed 
to hold TRPV1 in an inhibitory state (Prescott and Julius 2003). Fourth, arachidonic acid and other unsaturated fatty acids potentiate the 2APB-induced activation of TRPV3 (Hu et al. 2006). The great variability in the fatty acids used, to include triple bonded analogs may suggest a "loosely" specific activation mechanism that could be accounted for if these molecules cause a change in the membrane biophysical properties that are "sensed" by the channel. Polyunsaturated fatty acids also regulate TRPV channels in Caenorhabditis elegans (Kahn-Kirby et al. 2004) and TRPC channels in Drosophila (Chyb et al. 1999). Fifth, it has been proposed that mechano- and thermosensitive channels may be modulated by a common mechanism in a membrane-delimited fashion (Kung 2005).

2APB is a lipophilic molecule that possibly could accumulate in the membrane at high concentrations. There are several ways in which a lipophilic molecule such as 2APB could modulate TRP channels. First, when accumulated at high concentrations in the membrane, 2APB and its analogs could disrupt the interaction between various inhibitory phospholipids, such as $\mathrm{PIP}_{2}$. Second, the observation that $2 \mathrm{APB}$ and its analogs affect so many ionic channels and other membrane proteins suggests that 2 APB could act in a similar fashion as general anesthetics. A property of the anesthetics is that they usually affect the gating of many different ion channels by altering membrane properties (Antkowiak 2001). It has also been proposed that the best anesthetics accumulate at the membrane-water interface (North and Cafiso 1997). The high degree of lipophilicity along with the polarity of the $\mathrm{N} \rightarrow \mathrm{B}$ coordinate bond could result in the accumulation of 2 APB in this region. Exactly how 2APB affects different membrane properties remains to be investigated.

\section{Concluding Remarks}

Numerous studies have documented the effects of 2APB and its analogs on membrane channels. However, the mechanisms by which 2 APB regulate ion channels remain a mystery. New evidence suggests that the action of 2APB on TRP channels is not universal. While several TRP channels are inhibited, at least three of them, TRPV1-3, are stimulated by $2 \mathrm{APB}$. Some TRP channels are unaffected by $2 \mathrm{APB}$ and many more remain to be tested. The findings that 2APB activates TRPV1-3, while its analog DPTHF shows some selectivity for TRPV3 over TRPV1 and V2, make it promising that specific ligands may be made for TRPV2 and V3 through modification of various 2APB analogs. The identification of specific ligands for TRPV1 (e.g., capsaicin and resiniferatoxin) and TRPV4 (4aPDD) have not only facilitated the identification of physiological processes that these channels are involved in, but also made electrophysiological characterization of these channels more feasible. The recent increase in TRPV3-specific studies is directly related to the identification of 2APB as an agonist for TRPV1 and V3 activation (Gu et al. 2005; Chung et al. 2005; Zimmermann et al. 2005; Guatteo et al. 2005). More specific drugs would certainly accelerate the discovery of the physiological functions and mechanisms of regulation of these amazing channels.

\section{Acknowledgements}

Supported by US National Institutes of Health grants NS042183 and P30-NS045758. CKC is a recipient of the Meier Schlesinger Graduate Fellowship.

Handb Exp Pharmacol. Author manuscript; available in PMC 2015 June 06. 


\section{References}

Antkowiak B. How do general anaesthetics work? Naturwissenschaften. 2001; 88:201-213. [PubMed: 11482433]

Bender F, Mederos Y, Schnitzler M, Li Y, Ji A, Weihe E, Gudermann T, Schafer M. The temperaturesensitive ion channel TRPV2 is endogenously expressed and functional in the primary sensory cell line F-11. Cell Physiol Biochem. 2005; 15:183-194. [PubMed: 15665528]

Calixto JB, Kassuya CA, Andre E, Ferreira J. Contribution of natural products to the discovery of the transient receptor potential (TRP) channels family and their functions. Pharmacol Ther. 2005; 106:179-208. [PubMed: 15866319]

Chung MK, Lee H, Mizuno A, Suzuki M, Caterina MJ. TRPV3 and TRPV4 mediate warmth-evoked currents in primary mouse keratinocytes. J Biol Chem. 2004a; 279:21569-21575. [PubMed: 15004014]

Chung MK, Lee H, Mizuno A, Suzuki M, Caterina MJ. 2-Aminoethoxydiphenyl borate activates and sensitizes the heat-gated ion channel TRPV3. J Neurosci. 2004b; 24:5177-5182. [PubMed: 15175387]

Chung MK, Guler AD, Caterina MJ. Biphasic currents evoked by chemical or thermal activation of the heat-gated ion channel, TRPV3. J Biol Chem. 2005; 280:15928-15941. [PubMed: 15722340]

Chyb S, Raghu P, Hardie RC. Polyunsaturated fatty acids activate the Drosophila light-sensitive channels TRP and TRPL. Nature. 1999; 397:255-259. [PubMed: 9930700]

Clapham DE, Runnels LW, Strubing C. The TRP ion channel family. Nat Rev Neurosci. 2001; 2:387396. [PubMed: 11389472]

Delmas P, Wanaverbecq N, Abogadie FC, Mistry M, Brown DA. Signaling microdomains define the specificity of receptor-mediated InsP(3) pathways in neurons. Neuron. 2002; 34:209-220. [PubMed: 11970863]

Diver JM, Sage SO, Rosado JA. The inositol trisphosphate receptor antagonist 2aminoethoxydiphenylborate (2-APB) blocks $\mathrm{Ca}^{2+}$ entry channels in human platelets: cautions for its use in studying $\mathrm{Ca}^{2+}$ influx. Cell Calcium. 2001; 30:323-329. [PubMed: 11733938]

Dobrydneva Y, Blackmore P. 2-Aminoethoxydiphenyl borate directly inhibits store-operated calcium entry channels in human platelets. Mol Pharmacol. 2001; 60:541-552. [PubMed: 11502886]

Dobrydneva Y, Abelt CJ, Dovel B, Thadigiri CM, Williams RL, Blackmore PF. 2Aminoethoxydiphenyl borate as a prototype drug for a group of structurally related calcium channel blockers in human platelets. Mol Pharmacol. 2006; 69:247-256. [PubMed: 16214957]

Doly S, Fischer J, Salio C, Conrath M. The vanilloid receptor-1 is expressed in rat spinal dorsal horn astrocytes. Neurosci Lett. 2004; 357:123-126. [PubMed: 15036590]

Gu Q, Lin RL, Hu HZ, Zhu MX, Lee LY. 2-aminoethoxydiphenyl borate stimulates pulmonary C neurons via the activation of TRPV channels. Am J Physiol Lung Cell Mol Physiol. 2005; 288:L932-L941. [PubMed: 15653710]

Guatteo E, Chung KK, Bowala TK, Bernardi G, Mercuri NB, Lipski J. Temperature sensitivity of dopaminergic neurons of the substantia nigra pars compacta: involvement of transient receptor potential channels. J Neurophysiol. 2005; 94:3069-3080. [PubMed: 16014800]

Hanano T, Hara Y, Shi J, Morita H, Umebayashi C, Mori E, Sumimoto H, Ito Y, Mori Y, Inoue R. Involvement of TRPM7 in cell growth as a spontaneously activated $\mathrm{Ca}^{2+}$ entry pathway in human retinoblastoma cells. J Pharmacol Sci. 2004; 95:403-419. [PubMed: 15286426]

Hermosura MC, Monteilh-Zoller MK, Scharenberg AM, Penner R, Fleig A. Dissociation of the storeoperated calcium current ICRAC and the Mg-nucleotide-regulated metal ion current MagNuM. J Physiol. 2002; 539:445-458. [PubMed: 11882677]

Hu HZ, Gu Q, Wang C, Colton CK, Tang J, Kinoshita-Kawada M, Lee LY, Wood JD, Zhu MX. 2Aminoethoxydiphenyl borate is a common activator of TRPV1, TRPV2, and TRPV3. J Biol Chem. 2004; 279:35741-35748. [PubMed: 15194687]

Hu HZ, Xiao R, Wang C, Gao N, Colton CK, Wood JD, Zhu MX. Potentiation of TRPV3 channel function by unsaturated fatty acids. J Cell Physiol. 2006; 208:201-212. [PubMed: 16557504] 
Jia Y, Wang X, Varty L, Rizzo CA, Yang R, Correll CC, Phelps PT, Egan RW, Hey JA. Functional TRPV4 channels are expressed in human airway smooth muscle cells. Am J Physiol Lung Cell Mol Physiol. 2004; 287:L272-L278. [PubMed: 15075247]

Kahn-Kirby AH, Dantzker JL, Apicella AJ, Schafer WR, Browse J, Bargmann CI, Watts JL. Specific polyunsaturated fatty acids drive TRPV-dependent sensory signaling in vivo. Cell. 2004; 119:889900. [PubMed: 15607983]

Kashiba H, Uchida Y, Takeda D, Nishigori A, Ueda Y, Kuribayashi K, Ohshima M. TRPV2immunoreactive intrinsic neurons in the rat intestine. Neurosci Lett. 2004; 366:193-196. [PubMed: 15276245]

Kim CS, Kawada T, Kim BS, Han IS, Choe SY, Kurata T, Yu R. Capsaicin exhibits antiinflammatory property by inhibiting IkB-a degradation in LPS-stimulated peritoneal macrophages. Cell Signal. 2003; 15:299-306. [PubMed: 12531428]

Koulen P, Cai Y, Geng L, Maeda Y, Nishimura S, Witzgall R, Ehrlich BE, Somlo S. Polycystin-2 is an intracellular calcium release channel. Nat Cell Biol. 2002; 4:191-197. [PubMed: 11854751]

Kung C. A possible unifying principle for mechanosensation. Nature. 2005; 436:647-654. [PubMed: 16079835]

Lievremont JP, Bird GS, Putney JW Jr. Mechanism of inhibition of TRPC cation channels by 2aminoethoxydiphenylborane. Mol Pharmacol. 2005; 68:758-762. [PubMed: 15933213]

Liu B, Hui K, Qin F. Thermodynamics of heat activation of single capsaicin ion channels VR1. Biophys J. 2003; 85:2988-3006. [PubMed: 14581201]

Lucas P, Ukhanov K, Leinders-Zufall T, Zufall F. A diacylglycerol-gated cation channel in vomeronasal neuron dendrites is impaired in TRPC2 mutant mice: mechanism of pheromone transduction. Neuron. 2003; 40:551-561. [PubMed: 14642279]

Ma HT, Venkatachalam K, Rys-Sikora KE, He LP, Zheng F, Gill DL. Modification of phospholipase C-gamma-induced $\mathrm{Ca}^{2+}$ signal generation by 2-aminoethoxydiphenyl borate. Biochem J. 2003; 376:667-676. [PubMed: 14558886]

Maruyama T, Kanaji T, Nakade S, Kanno T, Mikoshiba K. 2APB, 2-aminoethoxydiphenyl borate, a membrane-penetrable modulator of Ins(1,4,5)P3-induced $\mathrm{Ca}^{2+}$ release. J Biochem (Tokyo). 1997; 122:498-505. [PubMed: 9348075]

Moqrich A, Hwang SW, Earley TJ, Petrus MJ, Murray AN, Spencer KS, Andahazy M, Story GM, Patapoutian A. Impaired thermosensation in mice lacking TRPV3, a heat and camphor sensor in the skin. Science. 2005; 307:1468-1472. [PubMed: 15746429]

Muraki K, Iwata Y, Katanosaka Y, Ito T, Ohya S, Shigekawa M, Imaizumi Y. TRPV2 is a component of osmotically sensitive cation channels in murine aortic myocytes. Circ Res. 2003; 93:829-838. [PubMed: 14512441]

Nilius B, Prenen J, Vennekens R, Hoenderop JG, Bindels RJ, Droogmans G. Pharmacological modulation of monovalent cation currents through the epithelial $\mathrm{Ca}^{2+}$ channel $\mathrm{ECaC} 1 . \mathrm{Br} \mathrm{J}$ Pharmacol. 2001; 134:453-462. [PubMed: 11588099]

Nöth, H. Some recent developments in boron-nitrogen chemistry. In: Brotherton, RJ.; Steinberg, H., editors. Progress in boron chemistry. Pergamon Press; New York: 1970. p. 211-311.

North C, Cafiso DS. Contrasting membrane localization and behavior of halogenated cyclobutanes that follow or violate the Meyer-Overton hypothesis of general anesthetic potency. Biophys J. 1997; 72:1754-1761. [PubMed: 9083679]

Patapoutian A, Peier AM, Story GM, Viswanath V. ThermoTRP channels and beyond: mechanisms of temperature sensation. Nat Rev Neurosci. 2003; 4:529-539. [PubMed: 12838328]

Peier AM, Reeve AJ, Andersson DA, Moqrich A, Earley TJ, Hergarden AC, Story GM, Colley S, Hogenesch JB, McIntyre P, Bevan S, Patapoutian A. A heat-sensitive TRP channel expressed in keratinocytes. Science. 2002; 296:2046-2049. [PubMed: 12016205]

Prakriya M, Lewis RS. Potentiation and inhibition of $\mathrm{Ca}^{2+}$ release-activated $\mathrm{Ca}^{2+}$ channels by 2aminoethyldiphenyl borate (2-APB) occurs independently of IP3 receptors. J Physiol. 2001; 536:3-19. [PubMed: 11579153]

Prakriya M, Lewis RS. Separation and characterization of currents through store-operated CRAC channels and $\mathrm{Mg}^{2+}{ }_{-}$inhibited cation (MIC) channels. J Gen Physiol. 2002; 119:487-507. [PubMed: 11981025] 
Prescott ED, Julius D. A modular $\mathrm{PIP}_{2}$ binding site as a determinant of capsaicin receptor sensitivity. Science. 2003; 300:1284-1288. [PubMed: 12764195]

Rettig SJ, Trotter J. Crystal and molecular structure of B, B-bis(p-tolyl)boroxazolidine and the orthorhombic form of B,B-diphenylboroxazolidine. Can J Chem. 1976; 54:3130-3141.

Rosado JA, Brownlow SL, Sage SO. Endogenously expressed Trp1 is involved in store-mediated Ca ${ }^{2+}$ entry by conformational coupling in human platelets. J Biol Chem. 2002; 277:42157-42163. [PubMed: 12196544]

Schindl R, Kahr H, Graz I, Groschner K, Romanin C. Store depletion-activated CaT1 currents in rat basophilic leukemia mast cells are inhibited by 2-aminoethoxydiphenyl borate. Evidence for a regulatory component that controls activation of both $\mathrm{CaT} 1$ and $\mathrm{CRAC}\left(\mathrm{Ca}^{2+}\right.$ release-activated $\mathrm{Ca}^{2+}$ channel) channels. J Biol Chem. 2002; 277:26950-26958. [PubMed: 12011062]

Strang CJ, Henson E, Okamoto Y, Paz MA, Gallop PM. Separation and determination of alpha -amino acids by boroxazolidone formation. Anal Biochem. 1989; 178:278-286.

Sydorenko V, Shuba Y, Thebault S, Roudbaraki M, Lepage G, Prevarskaya N, Skryma R. Receptorcoupled, DAG-gated $\mathrm{Ca}^{2+}$-permeable cationic channels in $\mathrm{LNCaP}$ human prostate cancer epithelial cells. J Physiol. 2003; 548:823-836. [PubMed: 12724346]

Tominaga M, Tominaga T. Structure and function of TRPV1. Pflugers Arch. 2005; 451:143-150. [PubMed: 15971082]

Tozzi A, Bengtson CP, Longone P, Carignani C, Fusco FR, Bernardi G, Mercuri NB. Involvement of transient receptor potential-like channels in responses to mGluR-I activation in midbrain dopamine neurons. Eur J Neurosci. 2003; 18:2133-2145. [PubMed: 14622174]

Trebak M, Bird GS, McKay RR, Putney JW Jr. Comparison of human TRPC3 channels in receptoractivated and store-operated modes. Differential sensitivity to channel blockers suggests fundamental differences in channel composition. J Biol Chem. 2002; 277:21617-21623. [PubMed: 11943785]

van Rossum DB, Patterson RL, Ma HT, Gill DL. Ca ${ }^{2+}$ entry mediated by store depletion, Snitrosylation, and TRP3 channels. Comparison of coupling and function. J Biol Chem. 2000; 275:28562-28568. [PubMed: 10878007]

Voets T, Prenen J, Fleig A, Vennekens R, Watanabe H, Hoenderop JG, Bindels RJ, Droogmans G, Penner R, Nilius B. CaT1 and the calcium release-activated calcium channel manifest distinct pore properties. J Biol Chem. 2001; 276:47767-47770. [PubMed: 11687570]

Xu H, Ramsey IS, Kotecha SA, Moran MM, Chong JA, Lawson D, Ge P, Lilly J, Silos-Santiago I, Xie Y, DiStefano PS, Curtis R, Clapham DE. TRPV3 is a calcium-permeable temperature-sensitive cation channel. Nature. 2002; 418:181-186. [PubMed: 12077604]

Xu SZ, Zeng F, Boulay G, Grimm C, Harteneck C, Beech DJ. Block of TRPC5 channels by 2aminoethoxydiphenyl borate: a differential, extracellular and voltage-dependent effect. $\mathrm{Br} \mathrm{J}$ Pharmacol. 2005; 145:405-414. [PubMed: 15806115]

Yue L, Peng JB, Hediger MA, Clapham DE. CaT1 manifests the pore properties of the calciumrelease-activated calcium channel. Nature. 2001; 410:705-709. [PubMed: 11287959]

Zhu X, Jiang M, Peyton M, Boulay G, Hurst R, Stefani E, Birnbaumer L. trp, a novel mammalian gene family essential for agonist-activated capacitative $\mathrm{Ca}^{2+}$ entry. Cell. 1996; 85:661-671. [PubMed: 8646775] 

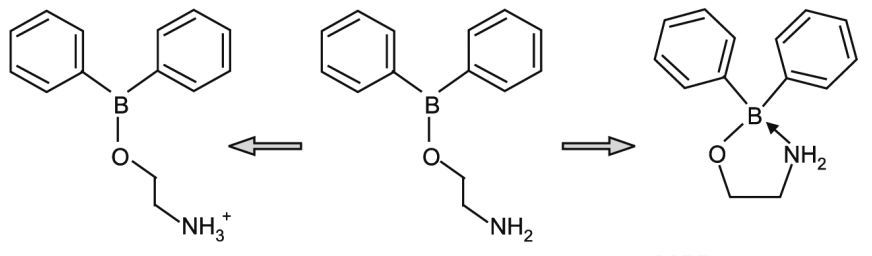

2APB monomer

2APB monomer

2APB monomer (open chain)

(ring)<smiles>c1ccc(B(OB(c2ccccc2)c2ccccc2)c2ccccc2)cc1</smiles>

diphenylboronic anhydride (DPBA)

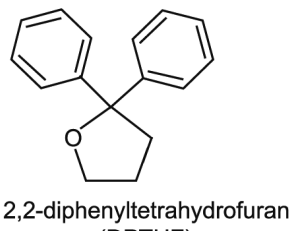

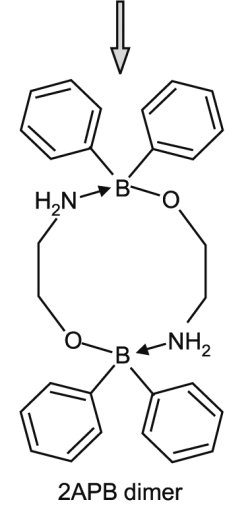<smiles>CN1CCO[B-](c2ccccc2)(c2ccccc2)N1C</smiles>

dimethyl 2APB<smiles>CN(C)CCOC(c1ccccc1)c1ccccc1</smiles>

diphenhydramine

Fig. 1.

Various forms of 2APB and several 2APB analogs. The nitrogen of the ethanolamine side chain on the 2APB monomer can become protonated (2APB monomer protonated) or form coordinate bonds with either an internal boron (2APB monomer ring) or the boron on another 2 APB molecule (2APB dimer). Most data support the 2APB monomer ring as the predominant form of $2 \mathrm{APB}$. The boron-containing $2 \mathrm{APB}$ analog diphenylboronic anhydride (DPBA) cannot be protonated. The nonboron-containing analog 2,2-diphenyltetrahydrofuran (DPTHF) is structurally related to the 2APB monomer ring. Diphenhydramine (Benadryl) is a nonboron-containing antihistamine that is structurally related to the 2APB monomer with the exception that 2 APB has a primary amine and diphenhydramine has a tertiary amine. Diphenhydramine is also structurally related to dimethyl 2APB with the exception that dimethyl 2APB should exist predominantly in the ring form, whereas diphenhydramine is unable to form a ring and could be protonated. All of these molecules have a tetrahedral geometry at the equivalent position to the boron of $2 \mathrm{APB}$ 